\title{
CONGENITAL ANOMALY OF OPTIC NERVE WITH FIELD DEFECTS*
}

\author{
BY \\ E S. PERKINS \\ Institute of Ophthalmology, University of London
}

An unmarried woman aged 20 attended hospital complaining of eye-strain after reading and close work. Four years previously she had had some attacks of headache associated with seeing flashing lights. The attacks had lessened in frequency since then. She was engaged in monotonous work as a capstan operator.

Examination.-Visual acuity was $6 / 12$ in the right eye and 6/9 in the left. The ocular movements, pupil reactions, and tension were normal. Both optic discs appeared to be deeply cupped although the cupping did not extend to the margins and the discs were of normal diameter (Fig.1). The rims of the discs appeared to be of normal colour, the vessels and rest of fundus appeared normal.

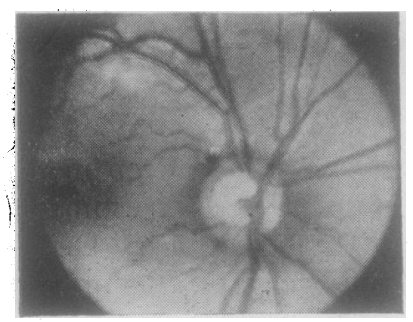

Fig. 1.-Fundus photograph of right optic disc showing well marked cup.

The central vision in both eyes improved to $6 / 6$ with a small myopic correction. Both peripheral fields showed some general constriction to a $3 / 330$ white object, and the central fields showed a ring scotoma extending from approximately $10^{\circ}$ to $20^{\circ}$ in both eyes to a 2/2000 and 20/000 white object (Fig. 2). The visual fields have been tested on three occasions by different observers with similar results each time.

The patient was referred for investigation to the glaucoma clinic at the Institute of Ophthalmology, where she was found to have an open angle and negative provocative tests. The maximum tension recorded throughout the tests was $22 \mathrm{~mm}$. $\mathrm{Hg}$ Schiötz.

\section{Discussion}

Curious field defects in a young woman are suggestive of hysteria, but the constancy of the defect on repeated examinations and the abnormal discs make this diagnosis unlikely.

Field defects associated with crater-like holes in the optic disc have been reported by Duke-Elder (1938), Greear (1942), Neame (1942), Rosen (1948), Redmond Smith (1953), and others. The appearances in this case are not like the

* Received for publication June 7, 1955. 


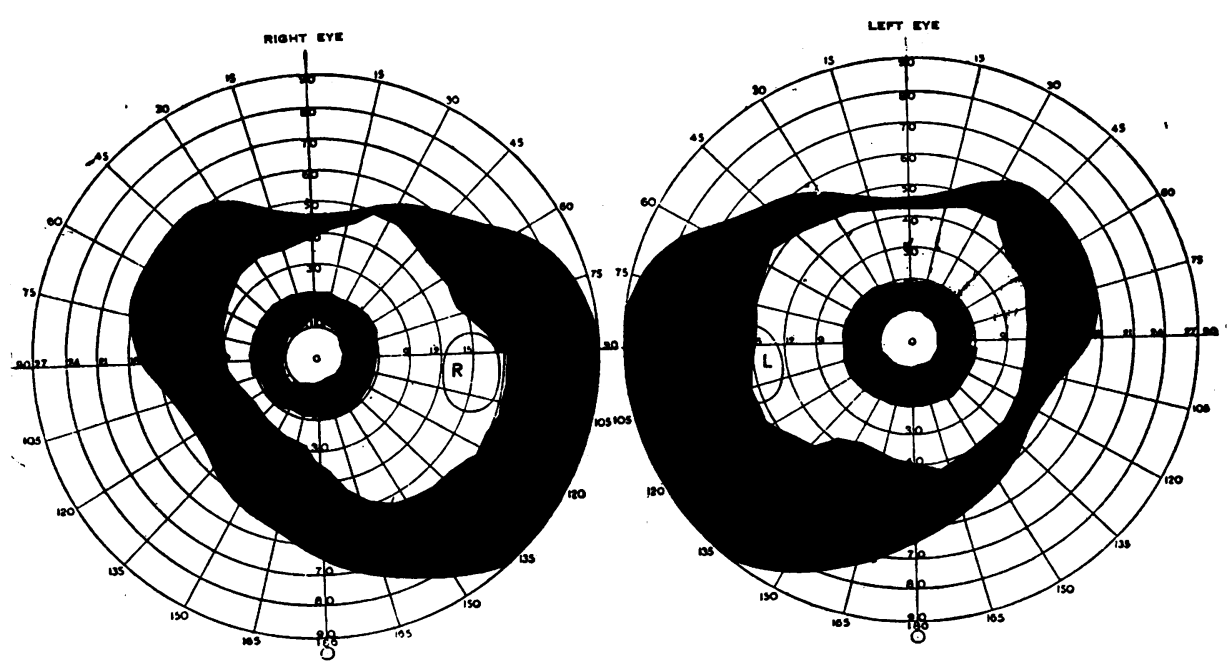

FIG. 2.-Composite visual field charts showing peripheral constriction and a ring scotoma associated with a congenital defect of the optic disc. Peripheral field plotted with $3 / 330$ white object. Central field plotted with 2/2000 white object.

usual discrete hole situated towards the temporal portion of the disc, but they are more similar to the cases described by Hillion (1911) and de Schweinitz (1911), except that in these two cases the visual fields were normal. It is probable that the defect is a type of coloboma in which field changes are common (Heine, 1927), in spite of the fact that the disc as a whole is not enlarged.

I am indebted to the Medical Illustration Department of the Institute of Ophthalmology for the fundus photograph.

\section{REFERENCES}

Duke-Elder, S. (1938). “Text-book of Ophthalmology”, vol. 2, p. 1261. Kimpton, London. Greear, J. N. (1942). Arch. Ophthal. (Chicago), 28, 467.

Hillion, H. (1911). Arch. Ophial., 31, 247.

Neame, H. (1942). Trans. ophthal. Soc. U.K., 62, 137.

ROSEN, E. (1948). British Journal of Ophthalmology, 32, 465.

SCHWEINITZ, G. E. DE (1911). Ophthal. Rec., 20, 385.

SMith, J. H. ReDMOND. (1953). British Journal of Ophthalmology, 37, 122.

Terrien, F. and Petit, P. (1901). Arch. Ophtal., 21, 405. 